\title{
A STUDY OF THE THERAPEUTIC VALUE OF A DIURETIC (THEOBROMIN SODIUM SALICYLATE OR DIU- RETIN) IN ACUTE EXPERIMENTAL NEPHRITIS (STUDY XVI)*
}

\author{
HENRY A. CHRISTIAN, M.D., AND JAMES P. O'HARE, M.D. \\ Boston
}

This study was undertaken with the idea of ascertaining whether or not there was any experimental evidence in support of the claim made frequently by clinicians that diuretics are contra-indicated in many cases of acute nephritis because they act to increase the work of the kidney and are irritants which may augment the pathological process already existent in the kidney. Clinicians holding this view regard diuretic drugs as harmful in cases of acute nephritis. If diuretics are harmful in acute nephritis animals with experimental renal lesions similar to those in acute nephritis in man should be unfavorably influenced by diuretic drugs. This series of experiments was planned to determine whether or not this was the case with one diuretic (theobromin sodium salicylate or diuretin).

Experiments were conducted chiefly along a comparative therapeutic line. An acute nephritis was produced in rabbits, and then a diuretic drug $^{1}$ (diuretin) was given to a part of the animals. The effect was judged mainly by the effect of the diuretic drug on the time elapsing between the dose of the substance used as a renal irritant and the death of the animal. In all of the experiments uranium nitrate was utilized as a renal irritant, since it produces an experimental nephritis in many respects similar to that occurring in human beings. Rabbits were the animals selected because a considerable number of experiments previously made for other purposes with these animals had given us a knowledge of the effects that might be expected from the use of such renal irritants.

* There have been published previously a series of studies on experimental cardiorenal disease by Drs. H. A. Christian, R. M. Smith and I. C. Walker: Studies I and II, Boston Med. and Surg. Jour., I908, clviii, 696, and 1908, clix, 8; Study III, Jour. Am. Med. Assn., 1909, liii. I792; and Studies IV, V, VI, VII, VIII, IX, X, XI, XII, XIII, XIV and XV, The Archives Int. Med., 1911, viii, 468-551.

* From the Laboratory of the Department of Theory and Practice of Physic, Harvard University.

* This work was done under a grant from the Proctor Fund for the Study of Chronic Diseases.

* Manuscript submitted for publication in The ARchrves March 31, 1913.

1. The drug used was purchased under the trade name of diuretin from two retail drug stores. No difference in effect was observed between the two. 
In Series 1 to 6 uranium nitrate was administered subcutaneously, and diuretin was used in watery solution administered with a stomach tube. In Series 7 to 11 uranium nitrate was given intravenously and intravenous administration of diuretin was employed. In all eighty-two rabbits divided into several series were used. Each series was divided into subject animals and controls. In some series the subject animals and controls were arranged in parallel groups of approximately equal body weights and were given equal doses of the drug. In most of the series the drugs used were given in doses varying in size according to the body weight of the animal.

In the first series, twelve rabbits rarying from $1,3 \% 0$ to 2,100 grams divided into pairs of approximately equal weights were used. All were given subcutaneously at twenty-four-hour intervals three doses of $5 \mathrm{mg}$. of uranium nitrate. After the first twenty-four hours one of each pair of the animals was given $0.4 \mathrm{gm}$. of diuretin by stomach tube, and this was repeated daily in most cases until the animal died. The animals which received uranium nitrate alone were regarded as controls for the subject animals that received uranium nitrate and diuretin. In this series the nephritis produced was a severe one and the dose of diuretin was large. As a result many of the animals died quickly, as shown by Table 1. The corresponding animal was killed at the time of death of the other animal in order to compare the anatomical changes in the two groups of animals. In this series no very striking difference exists as regards length of life between the animals with and without diuretin. Nine out of the twelve animals died four days or less after the first dose of uranium nitrate, and in two days or less after the last dose. It is true that the three animals killed to tally with their partners had received diuretin and this might suggest a favorable action for diuretin, but in the light of subsequent experiments this seems rather a matter of accident. the dosage of uranium nitrate being too great to allow of any sharp demarkation between treated and untreated animals.

In the second series (Table 2 ) nine rabbits were given a daily diet of $150 \mathrm{gm}$. of carrots per kilo of body weight. Uranium nitrate was given subcutaneously to all of the rabbits in a dosage of $3 \frac{1}{3} \mathrm{mgm}$. per kilo of body weight for two doses, twenty-four hours apart. To half of the rabbits was given daily $0.235 \mathrm{gm}$. of diuretin per kilo of body weight by means of a stomach-tube. In this series the animals receiving no diuretic outlived those receiving a diuretic (diuretin), as shown by Table 2 .

In the third series (Table 3) six rabbits were fed as in the second series and each received subcutaneously $3 \frac{1}{3} \mathrm{mgm}$. of uranium nitrate. For these animals the daily dose of diuretin was reduced to $28.6 \mathrm{mgm}$. per kilo, respectively. All animals not receiving a diuretic outlived those receiving a diuretic. The average length of life of the rabbits receiving 
uranium nitrate alone was 8.5 days, and of those receiving uranium and diuretin 5.3 days.

In the fourth series (Table 4) the rabbits were treated in the same way as in the third series. Of these, one rabbit receiving diuretin may be said to have survived, as it died on the twenty-second day from a complicating empyema. Omitting this animal, the other two with diuretin lived an arerage of eight and a half days, and two controls an average of nine days. Omitting this one surviving rabbit, this series shows a shortened duration of life for rabbits receiving the diuretic drug.

In the fifth series (Table 5) the rabbits were treated in the same way as in the fourth series. Three rabbits survived, two with diuretin treatment, and one with no treatment. Of the non-survivors, one with diuretin lived six Aays, and two controls lived an average of six and a half days.

In the sixth series, three doses of uranium nitrate $\left(3 \frac{1}{3} \mathrm{mgm}\right.$. per kilo of body weight) were given subcutaneously on successive days. Twentyfour hours after the last dose diuretin was given in doses half the size of those used in the preceding series, namely, $14.3 \mathrm{mgm}$. per kilo, and this was repeated daily. In this series all but one of the rabbits receiving diuretin survived, while the controls lived an average of ten days.

In the seventh series (Table 7 ) two doses of $31 / 2 \mathrm{mgm}$. of uranium nitrate per kilo of body weight were given intravenously at twenty-fourhour intervals, and to half of these rabbits was given intravenously on the day of the last dose of uranium $7 \mathrm{mgm}$. of diuretin in 2 c.c. of water per kilo of body weight, and on the next day $14 \mathrm{mgm}$. of diuretin in 4 c.e. of water per kilo of body weight. All of the rabbits died on the same day, two days after the last dose of uranium nitrate. These results indicated too large a dosage of uranium and so this was reduced in subsequent experiments to two doses intravenously instead of three. In this and subsequent series the rabbits were fed carrots and hay freely and had constant access to water.

In the eighth series (Table 8 ) two doses of $31 / 2 \mathrm{mgm}$. of uranium nitrate per kilo of body weight were given intravenously at twenty-fourhour intervals, and on the following morning $14 \mathrm{mgm}$. of diuretin in 4 c.c. of water per kilo of body weight were given intravenously, and this dosage was repeated morning and afternoon. Series 9 (Table 9), $10^{\circ}$ (Table 10) and 11 (Table 11) were treated in the same way. In these four series four animals survived; four with diuretin and none without diuretin. Of those dying during the experiments, sixteen received diuretin, and their average duration of life was 4.56 days; seventeen did not receive diuretin, and their average duration of life was 6.23 days.

In all of the rabbits which died, microscopic study showed in the kidney typical acute nephritis of the uranium nitrate type, with extensive 
necrosis of the tubular epithelium. Control experiments were made to show that diuretin in various doses by stomach-tube and intravenously, such as were used in these experiments, was not toxic for normal rabbits, and that water in intravenous doses of 4 c.c. per kilo of body-weight twice daily did not produce any appreciable disturbance in the rabbits, when each was given over periods longer than those used in the experiments described above.

\section{SUMMARY}

Diuretin was given to rabbits in which an acute nephritis had been produced with uranium nitrate. In forty-one rabbits the uranium nitrate was given subcutaneously and the diuretin by stomach-tube; in forty-one rabbits each drug was given intravenously. The amount of diuretin varied from large doses to $14 \mathrm{mgm}$. per kilo of body-weight. The latter is equivalent to $1 \mathrm{gm}$. dose for an average sized man. A few rabbits in the first series were killed as controls of rabbits dying; in all other series the rabbits were allowed to live as long as possible. Of the entire series, twelve survived, nine of which had had diuretin, three had not. In this number of survivors may be rabbits which, on account of high resistance, did not have a severe acute nephritis. Such resistant animals have been encountered in other sets of experiments. Of those dying under experiment, the average duration of life for those receiving uranium nitrate subcutaneously and diuretin by stomach tube was six days, of the controls (uranium nitrate subcutaneously) 6.94 days; the average duration of life for those receiving uranium nitrate and diuretin intravenously was 4.56 days; of the controls (uranium nitrate intravenously) 6.23 days.

\section{CONCLUSIONS}

Diuretin given to rabbits with a severe, fatal experimental nephritis, shortens the duration of life of these animals. On the other hand, nine out of twelve rabbits which survived the experiment had received diuretin. This work supports the view that in a severe acute nephritis a diuretic drug, such as diuretin is contra-indicated inasmuch as in the experiments diuretin shortened the lives of the animals. On the other hand, of the survivor's a large proportion (three-fourths) had received diuretin. 'This rather gives support to the view that in less severe cases diuretin may be beneficial and so justifies the cautious use of the drug in moderately severe cases of acute nephritis. In the survivors it is not certain that acute severe renal lesions were produced; consequently deductions from these relatively few survivors are of less value than from the larger number dying during the experiments. Of course, it is realized in making deductions such as the above that they may not be applicable directly to conditions in the human being, for due allowance must be made for the many differences between man and the lower animals. The experiments, however, certainly support the view that diuretin as a diuretic drug may be harmful in a case of acute nephritis. 


\section{Tables Showligi EfFect of Dicretix ox Rabbits with Experimental Niphritis \\ TABLE I}

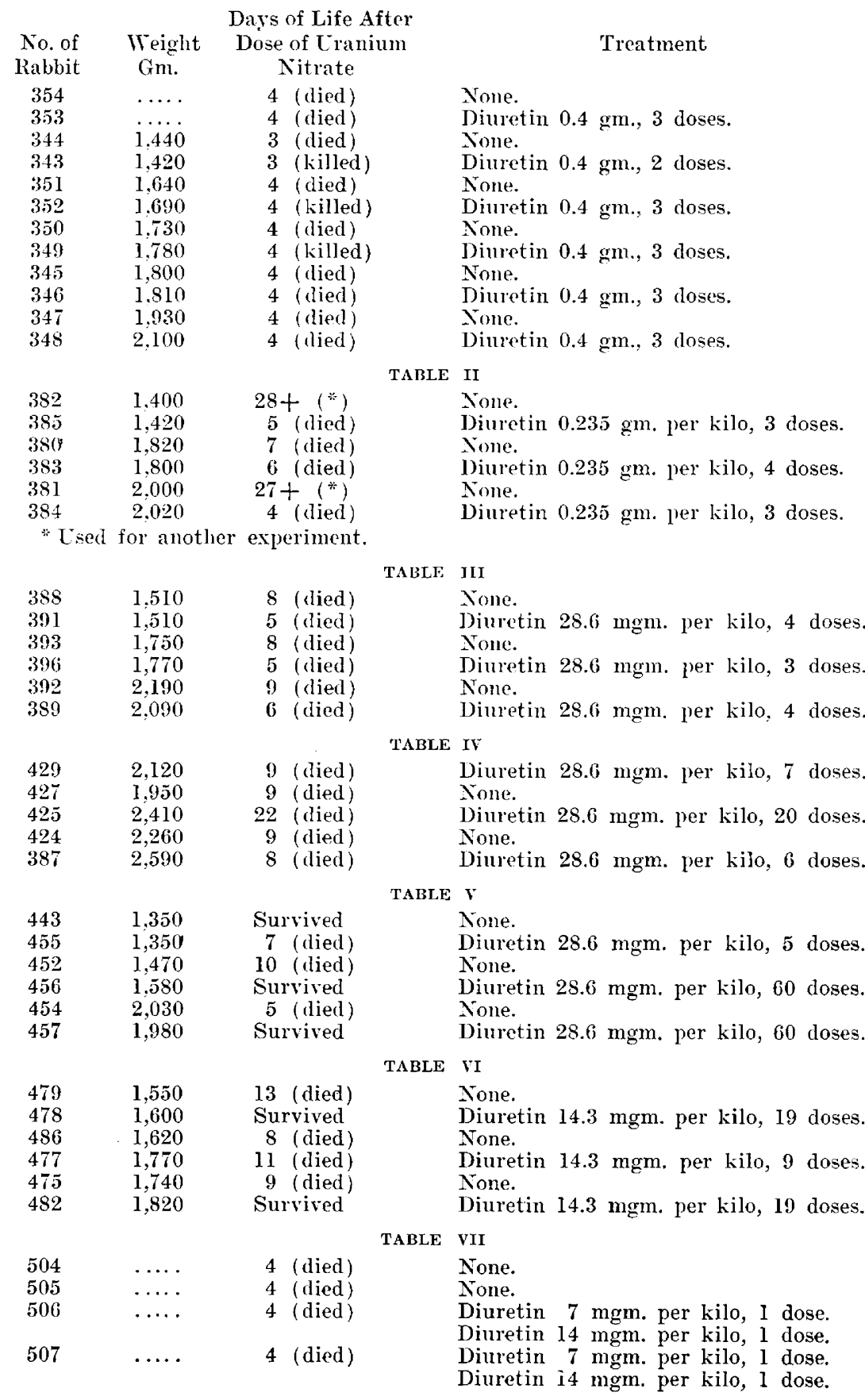


Tables Showing Effect of Diuretin on RabBits with Experimental NFPhRITIS

TABLE VIII

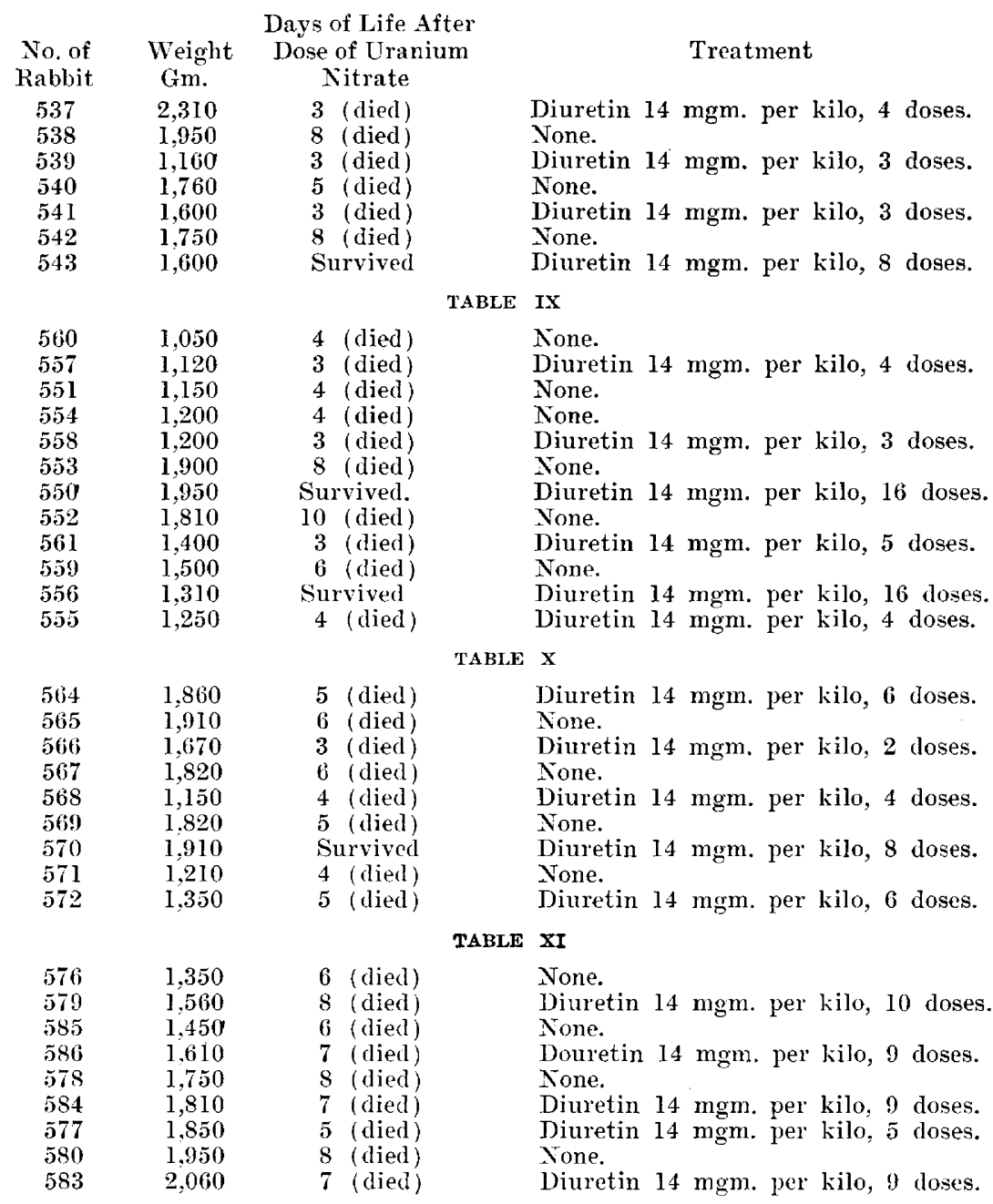

Peter Bent Brigham Hospital.-Carney Hospital. 